\title{
Research on Campus Network Equipment Environment Monitoring Based on Internet of Things
}

\author{
Jianwei Liu \\ Fujian Preschool Education College, Fuzhou, Fujian 350007, China \\ E-mail: liujianwei139@fjys.edu.cn
}

\section{Student paper}

Keywords: internet of things, campus network environment, equipment monitoring, ZigBee

Received: May 20, 2021

\begin{abstract}
The working environment of equipment has a great impact on the performance of equipment; therefore, it needs to be monitored and managed effectively. Based on the Internet of things (IoT), this study analyzed the monitoring of the campus network equipment environment. A monitoring system was designed, the design methods of software and hardware were analyzed, and the system was tested. The test results showed that the sensor used in the system had high accuracy, the temperature error was $\pm 0.5{ }^{\circ} \mathrm{C}$, the humidity error was within $0.5 \% \mathrm{RH}$, the data transmission performance was good, the transmission delay was between $8 \mathrm{~ms}$ and $9 \mathrm{~ms}$, and the average packet loss rate was 0.7\%. The test results verify the effectiveness of the designed system, and the system can be popularized and applied in the actual campus network.
\end{abstract}

Povzetek: Predstavljen je sistem za nadzor opreme v fakultetnem okolju z IoT.

\section{Introduction}

With the development of technology, the way of information acquisition has developed from manual to automatic. With the application of technologies such as radio frequency identification (RFID) and sensors [1], the Internet of things (IoT) has also developed rapidly [2]. IoT refers to the interconnection between things based on computer technology to form an intelligent network [3], through which data transmission [4], sharing and storage [5] are carried out, thus providing reliable intelligent management [6], including online monitoring, real-time positioning, remote alarm and other functions. IoT creates a new measurable, quantifiable world [7]. IoT has been widely valued by all countries in the world and has good applications in fields such as smart grid [8], industry [9], and medicine [10]. Marques et al. [11] proposed an IoTbased indoor air quality system, which combined Arduino, ESP8266, and XBee technologies. The system could be accessed through the web and mobile applications, and doctors could access the data to support the medical judgment. Jaco et al. [12] designed a vehicle positioning system combining RFID technology with a global system for mobile communication (GSM) technology, which obtained a reading range of about $31 \mathrm{~cm}$ in the lowfrequency communication range. After the field test, they found that the system could realize the positioning and tracking of vehicles. Ray et al. [13] proposed a thermal comfort index measurement system based on IoT, which intelligently integrated sensors and cloud services. They found that the system realized heterogeneous network communication and low power consumption, showing good performance. Zhu et al. [14] designed a smart home control system based on IoT, which could realize remote query and control of home applications. The system had the characteristics of reliable transmission and intelligent processing. The test showed that the system could run stably. With the popularity of the campus network, the equipment and scale in the network environment have been gradually expanded. The failure of the equipment will cause network paralysis, affecting the normal study and work of teachers and students. The working environment of equipment has a direct impact on the working state of equipment, such as temperature, humidity, etc. In the current campus network equipment management, manual duty is usually used, which is difficult to timely and comprehensively monitor the equipment. Therefore, based on the IoT, this study designed a campus network equipment environment monitoring system, which realized the collection and monitoring of equipment environment data and the intelligence and informatization of network equipment environment management through ZigBee and sensor technology. This work makes some contributions to improve the service quality of the campus network. 


\section{Design of environment monitoring system for campus network equipment based on IoT}

\subsection{Overall structure of the system}

A complete IoT mainly includes three parts: (1) perception layer: it takes equipment such as a single-chip microcomputer as the terminal node, carries various sensors, and configures the communication module to realize the communication between nodes, and it provides data to the upper later via the hardware interface; (2) network layer: it uploads the data obtained by the hardware interface to the application center through communication technology or transmission control protocol/internet protocol (TCP/IP) port; (3) application layer: it integrates technologies such as database and uses the interface provided by the lower layer to realize the control of the terminal node.

In the design of the system, the environmental parameters of the equipment were collected through temperature, humidity, and smoke sensors, and the ZigBee network was used for realizing the data transmission. Through the RJ232 interface, the information collected by the sensor was transmitted to the upper computer. Finally, in the application layer, the software system was developed by VB to realize the real-time monitoring of the equipment environment. The overall structure of the system is shown in Figure 1.

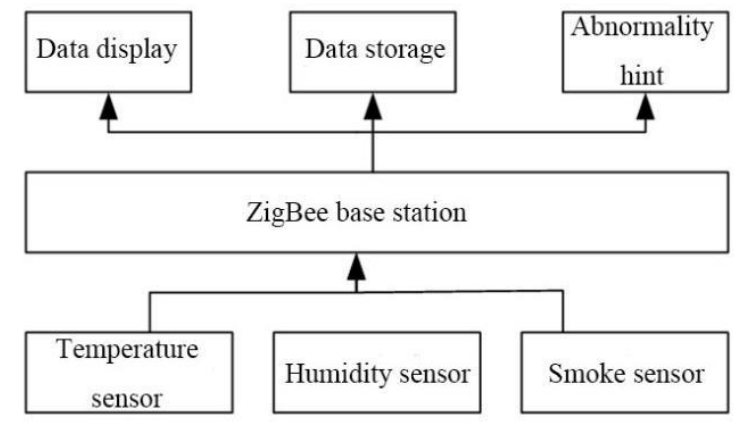

Figure 1: Monitoring system of campus network equipment environment.

\subsection{System hardware design}

The TM35 temperature sensor was used, with a working voltage of $2.7-5.5 \mathrm{~V}$ and an error of $\pm 2{ }^{\circ} \mathrm{C}$. When the ambient temperature was $25^{\circ} \mathrm{C}$, the output voltage of the temperature sensor was $250 \mathrm{MVC}$, the output proportional coefficient was $10 \mathrm{mV} /{ }^{\circ} \mathrm{C}$, and the measurement range was $-10{ }^{\circ} \mathrm{C}-100{ }^{\circ} \mathrm{C}$. The IH-3605 humidity sensor was used, with a relative humidity of $0 \%-100 \%$ and a corresponding output direct voltage of $0.8-4 \mathrm{~V}$. When the humidity sensor worked under $5 \mathrm{~V}$, the power consumption was only $200 \mu \mathrm{A}$, and the working temperature was $-40^{\circ} \mathrm{C}-85^{\circ} \mathrm{C}$. It had high precision, strong stability, and good chemical corrosion resistance; thus, it could provide stable data in equipment environmental monitoring. QJB gas monitoring alarm was used. When the detected gas appeared in the air, the platinum electrode would change, which would be converted into relay signal output. It had an antiinterference performance as it was less affected by temperature and humidity changes. Moreover, it had high sensitivity.

MSP430F5638 single-chip microcomputer was used as the processor, including two universal serial communication interfaces, four 16-bit timers, and a microcontroller with multiple input/output (I/O) pins. It had a working voltage of 1.8-3.6 V, low power consumption, long battery life, and fast response to wakeup; thus, it could adapt to long-time working situations.

In the choice of wireless communication protocol, there are four kinds of wireless communication protocol, as shown in Table 1.

\begin{tabular}{|l|l|l|l|l|}
\hline & $\begin{array}{l}\text { Working } \\
\text { frequency } \\
\text { band }\end{array}$ & $\begin{array}{l}\text { Transmiss } \\
\text { ion speed }\end{array}$ & $\begin{array}{l}\text { Power } \\
\text { consu } \\
\text { mption }\end{array}$ & $\begin{array}{l}\text { Effect } \\
\text { ive } \\
\text { range }\end{array}$ \\
\hline $\begin{array}{l}802.11 \\
\text { protocol }\end{array}$ & $2.4 \mathrm{GHz}$ & $11 \mathrm{Mbps}$ & $\begin{array}{l}100 \\
\mathrm{~mW}\end{array}$ & $100 \mathrm{~m}$ \\
\hline $\begin{array}{l}\text { Ultra } \\
\text { wide band } \\
\text { (UWB) } \\
\text { communi } \\
\text { cation }\end{array}$ & $\begin{array}{l}3.1 \mathrm{GHz}- \\
10.6 \mathrm{GHz}\end{array}$ & $480 \mathrm{Mbps}$ & $1 \mathrm{~mW}$ & $10 \mathrm{~m}$ \\
\hline $\begin{array}{l}\text { Bluetooth } \\
\text { protocol }\end{array}$ & $2.4 \mathrm{GHz}$ & $1-3 \mathrm{Mbps}$ & $\begin{array}{l}1-100 \\
\mathrm{~mW}\end{array}$ & $\begin{array}{l}10- \\
100 \mathrm{~m}\end{array}$ \\
\hline $\begin{array}{l}\text { ZigBee } \\
\text { protocol }\end{array}$ & $\begin{array}{l}868 / 915 \\
\mathrm{MHz}, 2.4\end{array}$ & $20,40 \mathrm{Kbps}$ & $\begin{array}{l}1-3 \\
\mathrm{~mW}\end{array}$ & $70 \mathrm{~m}$ \\
\hline
\end{tabular}

Table 1: Comparison of communication protocols.

It was seen from Table 1 that the power consumption of 802.11 protocol and Bluetooth protocol was large, while the power consumption of UWB communication was small, but its effective range was only $10 \mathrm{~m}$, which could not meet the communication distance requirements of the monitoring system. Therefore, this paper selected ZigBee protocol as the communication protocol and used CC2530 single-chip microcomputer produced by $\mathrm{T} 1$ company to send the collected data. The single-chip microcomputer consisted of an 8051 single-chip microcomputer and a radio-frequency (RF) transceiver and had a communication distance of $1000 \mathrm{~m}$ and a storage space of $256 \mathrm{~KB}$. It could realize long-distance communication, with stable networking performance and low price.

The battery part used two No. 5 batteries as the main power supply, which was easy to replace. The gateway part used the OMAP3730 chip produced by T1 company, which integrated two subsystems. The digital signal processing (DSP) subsystem had a highest working frequency of $800 \mathrm{MHz}$ and a maximum processing capacity of 6400 MIPS. The ARM subsystem used the ARM Coretex-A8 processor and had a highest frequency 
of $1000 \mathrm{MHz}$, which had reliable performance in data processing, receiving, and sending.

\subsection{Design of system software}

The development environment of the system was IAR Embedded Workbench for MCS-51 7.51A, and the programming language was $\mathrm{C}$ language. The sensor node collected the environmental parameters through the sensor and transmitted them to the upper computer through the wireless communication module to monitor various parameters. Before the node worked, the clock frequency of the CC2530 single-chip microcomputer was set to ensure the power supply stability of the voltage regulator, and the port of the CC2530 single-chip microcomputer was initialized to run the corresponding program. After the node initialization, different sensors were allowed to join the ZigBee network, collect the corresponding data, and send them to the monitoring center. In this study, the Niagara software was used as the development environment of the upper computer for secondary development to realize the real-time monitoring of the equipment environment.

\section{System test}

\subsection{Sensor accuracy test}

In environmental monitoring, temperature and humidity sensors have high requirements for accuracy, while smoke sensors only have two states, "yes (1)" and "no (0)", which is relatively simple. Therefore, this study mainly tested the accuracy of temperature and humidity sensors, collected five groups of data at different times and places, and compared the temperature and humidity collected by the sensors with the actual temperature and humidity. The results are shown in Table 2.

\begin{tabular}{|l|l|l|l|}
\hline \multicolumn{2}{|c|}{ Number } & $\begin{array}{l}\text { Temperature/ } \\
{ }^{\circ} \mathrm{C}\end{array}$ & $\begin{array}{l}\text { Humidity/\% } \\
\text { RH }\end{array}$ \\
\hline 1 & $\begin{array}{l}\text { The } \\
\text { sensor in } \\
\text { this study }\end{array}$ & 26.89 & 30.12 \\
\cline { 2 - 4 } & $\begin{array}{l}\text { Actual } \\
\text { situation }\end{array}$ & 27.31 & 30.29 \\
\hline 2 & $\begin{array}{l}\text { The } \\
\text { sensor in } \\
\text { this study }\end{array}$ & 25.33 & 28.96 \\
\cline { 2 - 4 } & $\begin{array}{l}\text { Actual } \\
\text { situation }\end{array}$ & 25.12 & 29.03 \\
\hline 3 & $\begin{array}{l}\text { The } \\
\text { sensor in } \\
\text { this study }\end{array}$ & 28.78 & 27.64 \\
\cline { 2 - 4 } & $\begin{array}{l}\text { Actual } \\
\text { situation }\end{array}$ & 28.56 & 27.33 \\
\hline 4 & $\begin{array}{l}\text { The } \\
\text { sensor in } \\
\text { this study }\end{array}$ & 23.46 & 34.12 \\
\cline { 2 - 4 } & $\begin{array}{l}\text { Actual } \\
\text { situation }\end{array}$ & 23.57 & 34.29 \\
\hline
\end{tabular}

\begin{tabular}{|l|l|l|l|}
\hline 5 & $\begin{array}{l}\text { The } \\
\text { sensor in } \\
\text { this study }\end{array}$ & 25.66 & 35.09 \\
\cline { 2 - 4 } & $\begin{array}{l}\text { Actual } \\
\text { situation }\end{array}$ & 26.07 & 34.87 \\
\hline
\end{tabular}

Table 2: Test results of sensor accuracy.

It was seen from Table 2 that the errors between the sensors used in this study and the actual result were very small in the comparison of the five groups of data, the temperature error was within $\pm 0.5^{\circ} \mathrm{C}$, and the humidity error was not more than $0.5 \% \mathrm{RH}$, indicating that the sensors with high accuracy could meet the usage requirement of the equipment environmental monitoring system and provide accurate and reliable data for the subsequent environmental monitoring.

\subsection{Network performance test}

The time delay of the transmission of the single-hop data between two nodes was tested. After the node joined the network, the coordinator sent a request to the third party and recorded the time as 1 . Then, the node received the request, processed it immediately, and returned the packet. The third-party captured the packet again and recorded the time of the process as 2 . The time difference between 1 and 2 was the transmission delay. Under different distances, the transmission delay of data is shown in Table 3 .

\begin{tabular}{|l|l|}
\hline Distance/m & Time delay/ms \\
\hline 10 & 8 \\
\hline 20 & 8 \\
\hline 30 & 9 \\
\hline 40 & 8 \\
\hline 50 & 9 \\
\hline 60 & 9 \\
\hline 70 & 8 \\
\hline 80 & 8 \\
\hline
\end{tabular}

Table 3: Data transmission delay.

It was seen from Table 3 that the data transmission time was between $8-9 \mathrm{~ms}$ in the single-hop range, which showed that the designed system had high transmission speed and good stability in the process of data transmission and could meet the needs of environmental monitoring of campus network equipment.

The packet loss rate of the network was tested. One gateway node, six sensor nodes, and six routing nodes were used. The collected data were forwarded to the gateway through the routing node. The test results are shown in Figure 2. 


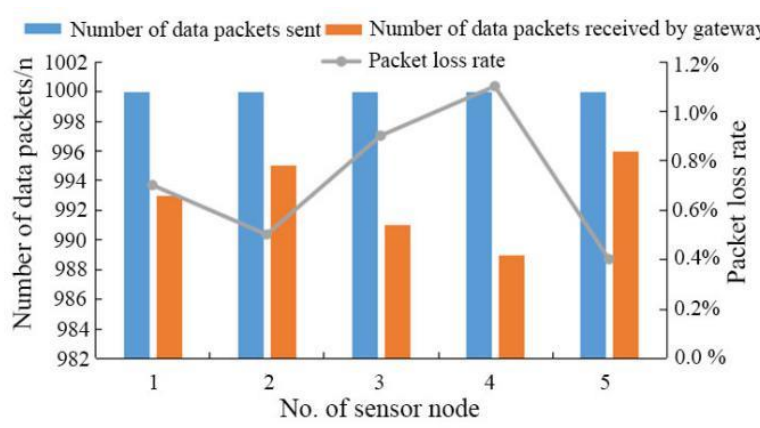

Figure 2: Test results of packet loss rate.

It was seen from Figure 2 that every sensor node sent 1000 packets, and the number of packets received by the gateway node was more than 900 , indicating that the network had relatively stable performance in the communication process. The packet loss rates of the five nodes were $0.7 \%, 0.5 \%, 0.9 \%, 1.1 \%$, and $0.4 \%$, respectively, and the average packet loss rate was $0.7 \%$, which verified the communication stability of the designed system.

\section{Discussion}

With the development of the Internet and other technologies and because of the advantages such as low power consumption, strong flexibility, and low cost, IoT has been more and more widely used in various fields of society [15], such as intelligent label [16], environmental monitoring [17], and intelligent control [18]. An intelligent label means labeling subjects with different technologies to distinguish them, for example, the bar code on commodities. Environmental monitoring means collecting and monitoring the information of subjects with technologies such as sensors, for example, monitoring of urban exhaust pollution. Intelligent control means controlling subjects through technologies such as sensors [19], for example, control of watering time and frequency of greenhouse. As the social demand for IoT increases, the research on IoT will be more extensive and in-depth.

Based on IoT, this study analyzed the monitoring of the campus network equipment environment, designed a monitoring system, and realized the real-time monitoring and judgment of the equipment working environment. First of all, the two sensors used in this study had good performance in accuracy, the error of the temperature sensor was $\pm 0.5^{\circ} \mathrm{C}$, and the error of the humidity sensor was $\pm 0.5 \% \mathrm{RH}$, which could meet the needs of the system in environmental monitoring. The test results of network performance showed that the time delay was between 8-9 $\mathrm{ms}$ in the process of data transmission, the transmission speed was high, the packet loss rate was low, and the average packet loss rate was $0.7 \%$, which showed that the system had high stability and could meet the needs in practical application.

Although this article has achieved some results in the monitoring of campus network equipment environment, there are still some shortcomings. In future work, the author will:

(1) further improve the stability of data communication;
(2) study the energy consumption of the system to ensure that the nodes can work permanently,

(3) search the module that can expand the transmission distance to improve transmission efficiency.

\section{Conclusion}

Based on IoT, this study designed an environment monitoring system of campus network equipment and tested it. The results showed that the system had high sensor precision, good network performance, high transmission speed, and low packet loss rate, which could be further promoted and applied in practice. This work is beneficial to the real-time monitoring and management of the campus network equipment environment.

\section{References}

[1] Al-Fuqaha A, Guizani M, Mohammadi M, Aledhari M, Ayyash M. (2015). Internet of Things: A Survey on Enabling Technologies, Protocols, and Applications. IEEE Communications Surveys \& Tutorials, 17, pp. 2347-2376. https://doi.org/10.1109/COMST.2015.2444095.

[2] Li S, Li D X, Zhao S. (2015). The internet of things: a survey. Information Systems Frontiers, 17, pp. 243-259.

https://doi.org/10.1016/j.comnet.2010.05.010.

[3] Singh K J, Kapoor D S. (2017). Create Your Own Internet of Things: A survey of IoT platforms. IEEE Consumer Electronics Magazine, 6, pp. 57-68. https://doi.org/10.1109/MCE.2016.2640718

[4] King J, Awad AI. (2016). A distributed security mechanism for resource-constrained IoT devices. Informatica, 40, pp. 133-143.

[5] Bali M, Tari A, Almutawakel A, Kazar O. (2020). Smart Design for Resources Allocation in IoT Application Service Based on Multi-agent System and DCSP. Informatica, 44, pp. 373-386. https://doi.org/10.31449/inf.v44i3.2962

[6] Whitmore A, Agarwal A, Xu L D. (2015). The Internet of Things-A survey of topics and trends. Information Systems Frontiers, 17, pp. 261-274. https://doi.org/10.1007/s10796-014-9489-2.

[7] Tran HA, Tran DQ, Nguyen G, Ha QT, Tong V, Mellouk A. (2018). SHIOT: A novel SDN-based framework for the heterogeneous Internet of Things. Informatica, 42(3). https://doi.org/10.31449/inf.v42i3.2245

[8] Viswanath S K, Yuen C, Tushar W, Li WT, Wen CK, $\mathrm{Hu}$ K, Chen C, Liu X. (2016). System Design of Internet-of-Things for Residential Smart Grid. IEEE Wireless Communications, 23, pp. 90-98.

[9] Trappey A J C, Trappey C V, Govindarajan U H, Chuang AC, Sun J. (2016). A review of essential standards and patent landscapes for the Internet of Things: A key enabler for Industry 4.0. Advanced Engineering Informatics, 33, pp. 208-229. https://doi.org/10.1016/j.aei.2016.11.007.

[10] Islam S, Kwak D, Kabir M H, Hossain M, Kwak KS. (2015). The Internet of Things for Health Care: A 
Comprehensive Survey. IEEE Access, 3, pp. 678708. https://doi.org/10.1109/ACCESS.2015.2437951.

[11] Marques G, Pitarma R. (2016). An Indoor Monitoring System for Ambient Assisted Living Based on Internet of Things Architecture. International Journal of Environmental Research and Public Health, 13, pp. 1152-. https://doi.org/10.3390/ijerph13111152.

[12] Jaco P, Reza M. (2016). Accurate Vehicle Location System Using RFID, an Internet of Things Approach. Sensors, 16, pp. 825. https://doi.org/10.3390/s16060825.

[13] Ray PP. (2016). Internet of Things Cloud Enabled MISSENARD Index Measurement for Indoor Occupants. Measurement, 92, pp. 157-165. https://doi.org/10.1016/j.measurement.2016.06.014

[14] Zhu J, Jia X, Mei X Q. (2015). Smart Home Control System Based on Internet of Things. Applied Mechanics and Materials, 738-739, pp. 233-237.

[15] Ma H, Liu L, Zhou A, Zhao D. (2017). On Networking of Internet of Things: Explorations and Challenges. IEEE Internet of Things Journal, 3, pp. 441-452. https://doi.org/10.1109/JIOT.2015.2493082.

[16] Marktscheffel T, Gottschlich W, Popp W, Werli P, Fink SD, Bilzhause A, de Meer H. (2016). QR code based mutual authentication protocol for Internet of Things. Workshop on IoT-SoS: Internet of Things Smart Objects \& Services, pp. 1-6. https://doi.org/10.1109/WoWMoM.2016.7523562.

[17] Kokkonis G, Psannis K E, Roumeliotis M, Schonfeld D. (2017). Real-time wireless multisensory smart surveillance with 3D-HEVC streams for internet-ofthings (IoT). The Journal of Supercomputing, 73, pp. 1044-1062. https://doi.org/10.1007/s11227-0161769-9.

[18] Francisco-Pastor F P, García-Chamizo JM, NietoHidalgo M, Mora-Pascual J, Mora-Martínez J. (2016). Developing Ubiquitous Sensor Network Platform Using Internet of Things: Application in Precision Agriculture. Sensors, 16, pp. 1141. https://doi.org/10.3390/s16071141.

[19] Kawakami T, Ishi Y, Yoshihisa T, Teranishi Y. (2015). A Churn Resilience Technique on P2P Sensor Data Stream Delivery System Using Distributed Hashing. Informatica: An International Journal of Computing and Informatics, 39, pp. 355363. https://doi.org/10.1109/3PGCIC.2014.114 
